Original Article

\title{
DESIGN, DEVELOPMENT AND EVALUATION OF DILTIAZEM HYDROCHLORIDE LOADED NANOSPONGES FOR ORAL DELIVERY
}

\section{B. NARASIMHA RAO*, K. RAVINDRA REDDY, S. RAHATH FATHIMA, P. PREETHI}

Department of Pharmaceutics, P. Rami Reddy Memorial College of Pharmacy, Kadapa 516003, Andhra Pradesh, India Email: simham1985@gmail.com

Received: 13 Jun 2020, Revised and Accepted: 16 Aug 2020

\section{ABSTRACT}

Objective: In the current investigation,nanosponges were set up by emulsion solvent diffusion technique utilizing ethyl cellulose and $\beta$-cyclodextrin as polymers.

Methods: Diltiazem hydrochloride is taken as model medication for considering different nanosponge formulations. The similarity of different formulation segments was set up by Fourier Transform Infra-Red (FTIR) spectroscopy. Molecular size, surface morphology, entrapment efficiency and drug content of nanosponges were analyzed. Shape and surface morphology of the nanosponges were inspected utilizing scanning electron microscopy.

Results: Molecule size of formulated nanosponges was seen in the scope of 186 to $476 \mathrm{~nm}$. Scanning electron microscopy uncovered the permeable, round nature of the nanosponges. The drug content of nanosponges for ethyl cellulose containing formulations was seen as in the scope of 62.25 to $85.11 \%$ and for the $\beta$-cyclodextrin containing details were seen as in the scope of $65.18-89.67 \%$. The percentage entrapment effectiveness of nanosponges for ethyl cellulose containing formulations were seen as in the scope of 54.18 to $79.49 \%$ and for the $\beta$-cyclodextrin containing details were seen as in the scope of 58.21-83.45\%. In vitro drugreleasefindings demonstrated that at $12 \mathrm{~h}$ ethyl cellulose containing formulations discharged the drug in the scope of $57.27-89.09 \%$ and for the $\beta$-cyclodextrin containing formulations discharged in the scope of $73.94-93.26 \%$.

Conclusion: Sustained drugreleasefrom formulations is supported if there is an occurrence of ethyl cellulose in the formulations rather with plans containing $\beta$-cyclodextrin.

Keywords: Diltiazem hydrochloride, $\beta$-Cyclodextrin, Ethyl cellulose, Poly vinyl alcohol, Scanning Electron Microscopy, UV Spectroscopy

(C) 2020 The Authors. Published by Innovare Academic Sciences Pvt Ltd. This is an open access article under the CC BY license (http://creativecommons.org/licenses/by/4.0/) DOI: http://dx.doi.org/10.22159/ijcpr.2020v12i5.39784. Journal homepage: https://innovareacademics.in/journals/index.php/ijcpr

\section{INTRODUCTION}

The drug delivery technology has unquestionably another concern for drugs by giving them new life through their therapeutic targets. Target oriented drug administration with upgrades in therapeutic efficacy, decrease in side-effects and enhanced dosing routine, will be the main patterns in the region of therapeutics [1]. Targeted drug delivery suggests for specific and compelling confinement of pharmacologically active moiety at pre recognized objective in therapeutic concentration, while limiting its entrance to non-target typical cell linings and in this manner limiting harmful impacts and augmenting therapeutic index of the drug [2-5].

Nanospongesare permeable polymeric delivery systems that are little round particles with enormous permeable surface [6]. Nanosponges (NSs) are a significant part to control the pace of delivery of active agent to the predetermined site by little size and productive carrier attributes. NSs are nonmutagenic, nonallergenic, nonirritant, and nontoxic $[7,8]$.

The expression "Nanosponge" signifies the nanoparticles with permeable structures. Nanosponges are little sponges almost equal to the size of virus with a normal breadth under $1 \mu \mathrm{m}$ [9]. Owing to their little size and penetrable nature they can tie poorly soluble drugs inside the framework and enhance their bioavailability by altering the pharmacokinetic limits of actives [10,11].

The nanosponges are a three-dimensional framework (backbone) or system of polyester that are fit for degrading normally. These polyesters are blended in with a crosslinker in a solutionto form nanosponges [12]. Here, the polyester is commonly biodegradable, so it breaks down in the body decently. When the scaffold of nanospongesbreaks down, it discharges the medication particles which are stacked, in an injurious fashion [13].
Nanosponges are smaller in nature and are little particles with penetrable surface can be considered as oral, parenteral and topical dosage forms. Nanosponges meant for oral administration, might be scattered in a framework of excipients, diluents, anticaking agents and lubricants to build up appropriatetablets or capsules of them and the significant advantages of these dosage forms are reduced drug dose, decrease in toxicity and improving patient consistence by delayed release [14-16]. For parenteral administration, these can be essentially blended in with sterile water, saline or different watery solutions. Further, nanosponges can be successfully added to topical hydrogel for topical application $[17,18]$.

\section{MATERIALS AND METHODS}

Diltiazem hydrochloride, $\beta$-Cyclodextrin and Ethyl cellulose obtained from Yarrow chemicals limited, Mumbai. Polyvinyl alcohol and Dichloromethane procured from SD fine chemicals, India.

\section{Preparationof diltiazem $\mathrm{HCl}$ nanosponges}

Diltiazem $\mathrm{HCl}$ nanosponges were set up by the emulsion solvent diffusion strategy. DTZ and EC/ $\beta$-Cyclodextrin were disintegrated in DCM (Phase 1), while Phase 2 was set up by adding PVA to refined water. Stage 1 and Phase 2 were put independently on an magnetic stirrer for $15 \mathrm{~min}$. Stage 1 was added gradually to Phase 2 with mixing and afterward left them for $15 \mathrm{~min}$ on the stirrer at room temperature. The blend was homogenized at various velocities for 2 h. From that point onward, it was sifted. The shaped nanosponges were dried at $40{ }^{\circ} \mathrm{C}$ for $12 \mathrm{~h}$

Preformulation studies

i) Identification of drug

The got sample drug was inspected by Infrared absorption spectral investigation and was contrasted with the reference standard IR 
range of Diltiazem $\mathrm{HCl}$. IR Spectra of medication and mixes were recorded on a FTIR (Bruker, Germany) in the scope of 4000-400 Cm1 utilizing potassium bromide discs.

\section{ii) Determination of melting point}

Melting point of Diltiazem $\mathrm{HCl}$ was found by open capillary technique. Melting-point apparatus is most regularly utilized for the assurance of the melting point of a solid. A couple ofcrystals of the compound are put in a slight walledcapillary tube $10-15 \mathrm{~cm}$ long about $1 \mathrm{~mm}$ in inside breadth, and shut down towards one side.

\section{iii) Construction of calibration curve of diltiazem $\mathrm{HCl}$}

A precisely weighed $100 \mathrm{mg}$ of Diltiazem hydrochloride was dissolved in water and made up to $100 \mathrm{ml}$ in volumetric flask (Stock solution-I $1000 \mu \mathrm{g} / \mathrm{ml}$ ). From this, $10 \mathrm{ml}$ of solution was pipetted out and made up to $100 \mathrm{ml}$ volumetric flask (Stock solution-II $100 \mu \mathrm{g} / \mathrm{ml}$ ). From this solution $0.2,0.4,0.6,0.8,1.0,1.2,1.4,1.6,1.8$ $2.0 \mathrm{ml}$ were pulled back and diluted to $10 \mathrm{ml}$ to give $2,4,6,8,10,12$, $14,16,18,20 \mu \mathrm{g} / \mathrm{ml}$ separately andmeasured the absorbance at 237 nm.

Table 1: Composition of nanosponges of diltiazem HCl (F1 to F10)

\begin{tabular}{|c|c|c|c|c|c|c|}
\hline \multirow[t]{2}{*}{ Formulationcode } & \multicolumn{6}{|c|}{ Composition } \\
\hline & DrugMg & Ethyl cellulosegm & PVAgm & $\beta$-cyclodextrin gm & Dichloromethane (ml) & Water(ml) \\
\hline F1 & 30 & 0.3 & 0.3 & - & 20 & 100 \\
\hline $\mathrm{F} 2$ & 30 & 0.6 & 0.5 & - & 20 & 100 \\
\hline F3 & 30 & 0.6 & 0.7 & - & 20 & 100 \\
\hline $\mathrm{F} 4$ & 30 & 0.9 & 0.9 & - & 20 & 100 \\
\hline F5 & 30 & 1.2 & 1.2 & - & 20 & 100 \\
\hline F6 & 30 & - & 0.3 & 0.3 & 20 & 100 \\
\hline F7 & 30 & - & 0.5 & 0.6 & 20 & 100 \\
\hline F8 & 30 & - & 0.7 & 0.6 & 20 & 100 \\
\hline F9 & 30 & - & 0.9 & 0.9 & 20 & 100 \\
\hline F10 & 30 & - & 1.2 & 1.2 & 20 & 100 \\
\hline
\end{tabular}

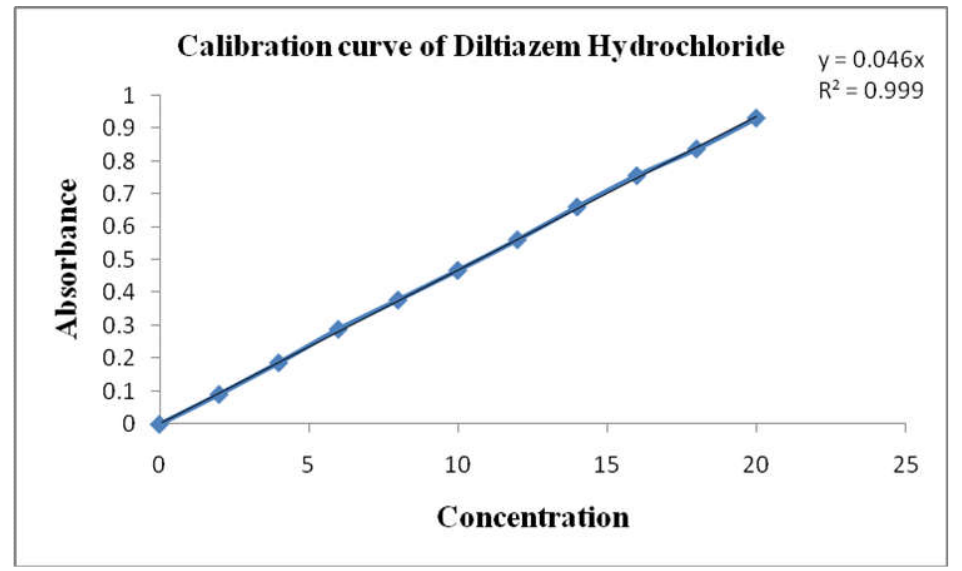

Fig. 1: Calibration curve of diltiazem $\mathrm{HCl}$

Characterization of diltiazem hydrochloride nanosponges

\section{Morpholog}

For SEM studies, one drop of nanosponge preparation was set on the stab secured with clean glass and covered with gold. It was later seen under the scanning electron magnifying lensat quickening voltage of $20 \mathrm{KV}$ and photomicrographs of appropriate amplification was gotten.

\section{Particle size}

Average molecule measurement of prepared nanosponge preparations was resolved utilizing dynamic light scattering technique (zeta sizer, Malvern, ZSP nano) following a previous portrayed technique. Aqueous dispersions of NS were appropriately diluted for scattering force at $25{ }^{\circ} \mathrm{C}$. Tests were kept in expendable cuvette and estimations were made at $372.0 \mathrm{kcps}$ (check rate) for $20 \mathrm{~s}$.

\section{Drug content}

Drug content consistency was resolved as triplicate by dissolving the Nan sponges in methanol and broke down Nan sponges were experienced centrifugation at 3000rpm for $2 \mathrm{~h}$ and separated with whatmann channel paper $(0.45 \mu \mathrm{m}$, Whatman, Maidstone, UK). The solution was diluted to Beer's range and seen in UVSpectrophotometer.

\section{Entrapment efficiency}

The amount of Diltiazem $\mathrm{HCl}$ in the formulation was dictated by UV investigation after disturbance of the vesicles with Triton X-100 $(0.5 \% \mathrm{w} / \mathrm{w})$. The vesicle/Triton X-100 arrangement was centrifuged at $10,000 \mathrm{rpm}$ at $40 \mathrm{C}$ for $10 \mathrm{~min}$. The supernatant was sifted. The capture efficiencies and the stacking efficiencies of the Diltiazem $\mathrm{HCl}$-stacked formulatins were determined by UV.

\section{In vitro drug release studies}

The in vitro penetration behavior of Diltiazem $\mathrm{HCl}$ from all nanosponges plans were explored utilizing cellophane layer (Molecular weight cut of 12000-14000). The vertical kind of the Franz Diffusion cell was planned, manufactured, and approved preceding the saturation study. The cellophane film was mounted on a diffusion cell assembly with anoperative dissemination region of $2.303 \mathrm{~cm}$. The receptor compartment comprised of a $22.5 \mathrm{ml}$ phosphate buffer at $\mathrm{pH} 6.8$, stirred at $100 \mathrm{rpm}$, and was kept up at $37 \pm 0.5{ }^{\circ} \mathrm{C}$ all through the analyses. The prepared NS formulation was applied to the layer in the donor compartment. An aliquot of test was pulled back at reasonable time spans and supplanted 
promptly with an equivalent volume of new diffusion medium. The total amount that permeated over the cellophane film was determined and plotted against time.

\section{RESULTS AND DISCUSSION}

The IR spectrum of wholesome drug was seen as like that of standard range of Diltiazem $\mathrm{HCl}$. The spectrum of Diltiazem $\mathrm{HCl}$ exhibits the accompanying groups at their frequencies appeared at $1037,1330,1412,1586,2923,3108 \mathrm{~cm}-1$. The melting point of Diltiazem $\mathrm{HCl}$ was found to be $212^{\circ} \mathrm{C}$ which consented to the $\mathrm{BP}$ guidelines. Compatibility investigations of wholesome drug Diltiazem $\mathrm{HCl}$ with polymers were completed past formulation of Nanosponges. All the distinguishing peaks of Diltiazem $\mathrm{HCl}$ were available in spectra at particular frequency. Hence, showing similarity among medication and polymers. It illustrates that there was no huge change in the chemical reliability of the drug.

\section{Morphology}

The readied Nanosponges were experienced morphological examinations by utilizing optical microscopic technique. Little amount of test was spread over clean slide. The slide was engaged under optical light and pictures were snapped by utilizing optical microscopy joined with Dewinter Microscopic camera programming. As indicated by morphological assessment investigation, all vesicles types appeared to have a circular or oval molded. These oval-molded vesicles may have come about because of the Nanosponges' distortion, which may happen during the sample readiness.

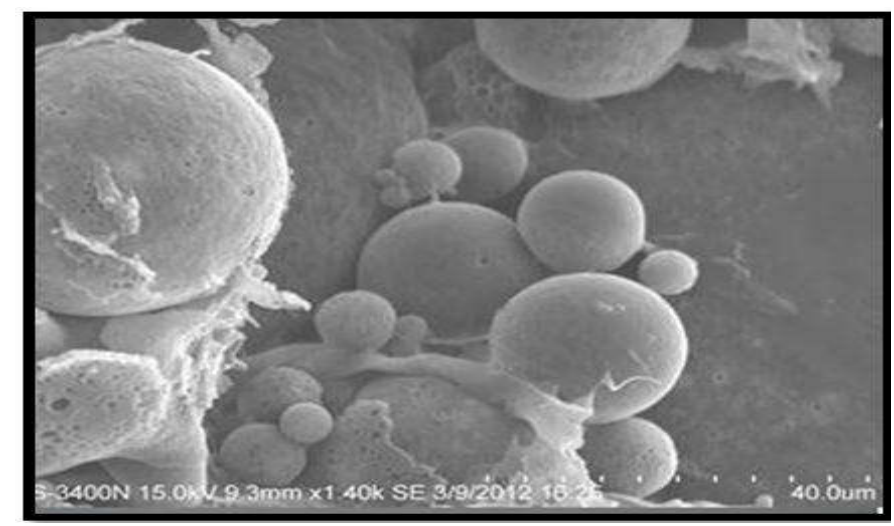

Fig. 2: Sem image of nanosponges

Table 2: Particle size, entrapment efficiency of F1 to F10 formulations

\begin{tabular}{lllll}
\hline S. No. & Formulation code & Particle size (nm) & Drug content (\%) & Entrapment efficiency (\%) \\
\hline 1 & F1 & 186 & 70.44 & 63.51 \\
2 & F2 & 222 & 85.11 & 79.49 \\
3 & F3 & 284 & 84.08 & 76.34 \\
4 & F4 & 345 & 73.65 & 67.83 \\
5 & F5 & 389 & 62.25 & 54.18 \\
6 & F6 & 250 & 65.18 & 58.21 \\
7 & F7 & 323 & 73.49 & 67.11 \\
8 & F8 & 376 & 83.68 & 76.04 \\
9 & F9 & 410 & 89.67 & 83.45 \\
10 & F10 & 476 & 81.24 & 74.62 \\
\hline
\end{tabular}

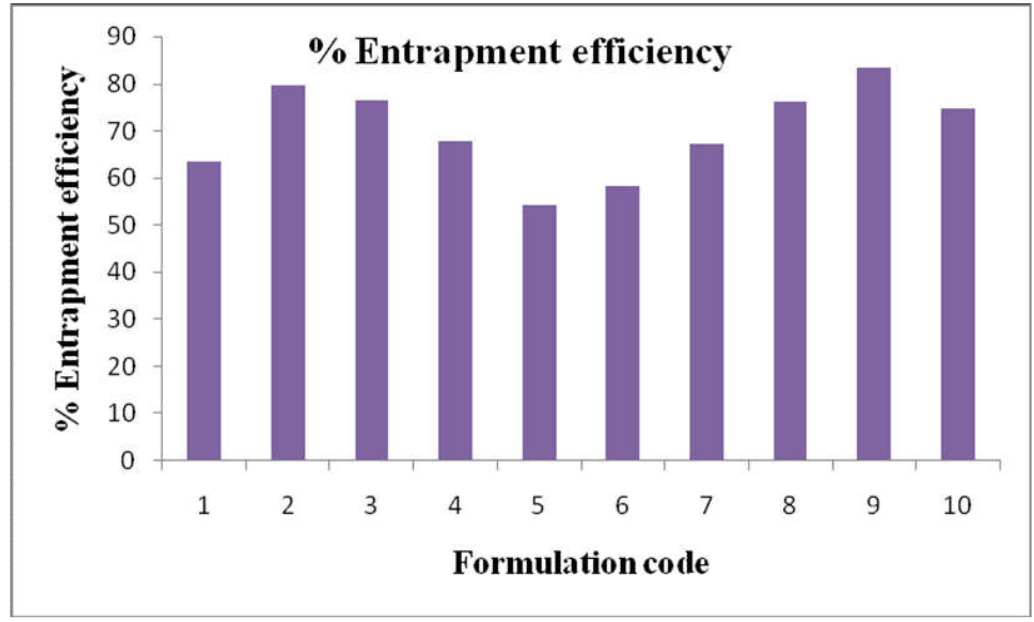

Fig. 3: Entrapment efficiency of F1 to F10 formulations 
The molecule size of the nanosponge was governed by optica microscopy and the nanosponges were seen as uniform in size. Particle size of Nanosponges containing ethyl cellulose was found to be in the range of $186 \mathrm{~nm}$ to $389 \mathrm{~nm}$. Nanosponges containing $\beta$-Cyclodextrinwas found to be in the range of $250 \mathrm{~nm}$ to $476 \mathrm{~nm}$ respectively. The normalparticle size was significantly influenced by the drug to polymer proportion. The moderately littler molecule size is because of lower strength of polymer giving lesser opportunity to droplet arrangement. Thus, we could see that the particle size increases as the concentration of ethyl cellulose and $\beta$-cyclodextrin increases. The drug content of nanosponges for ethyl cellulose containing formulations were found to be in the range of 62.25 to $85.11 \%$ and for the $\beta$-cyclodextrin containing formulations were found to be in the range of $65.18-89.67 \%$. The percentage Entrapment efficiency of nanosponges for ethyl cellulose containing formulations were found to be in the range of 54.18 to $79.49 \%$ and for the $\beta$-cyclodextrin containing formulations were found to be in the range of $58.21-83.45 \%$. The entrapment efficiency of the nanosponges was found to increase with growing polymer concentration. This could be due to the expansion of drug capturing limit of nanosponges as the polymer strength rose. Nanosponges with $0.3 \%$ EC and $\beta$-CD showed $63.51 \%$ and $58.21 \%$ entrapment efficiency respectively, which improved to $67.83 \%$ and $83.45 \%$ respectively when the polymer strength rose to $0.9 \%$ respectively.

\section{In vitro drug release studies}

The in vitro drug release of Diltiazem $\mathrm{HCl}$ was acted in phosphate buffer $\mathrm{pH}$ 7.4. The invitro discharge profile of Diltiazem $\mathrm{HCl}$ was primarily influenced by type and measure of polymer utilized. In vitro drug release investigations demonstrated that at $12 \mathrm{~h}$ ethyl cellulose containing formulations discharged the medication in the scope of $57.27-89.09 \%$ and for the $\beta$-cyclodextrin containing details drug discharged in the scope of $73.94-93.26 \%$. Drug release was sustained in case of ethyl cellulose formulations compared to formulations containing $\beta$-cyclodextrin.

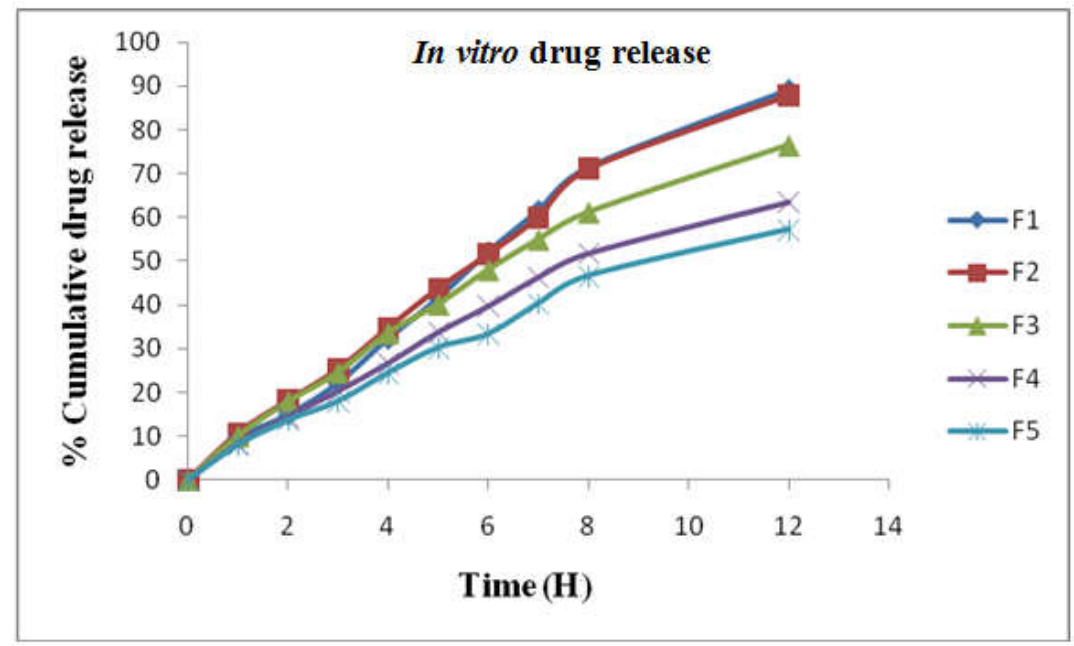

Fig. 4: In vitro diffusion studies for F1 to F6

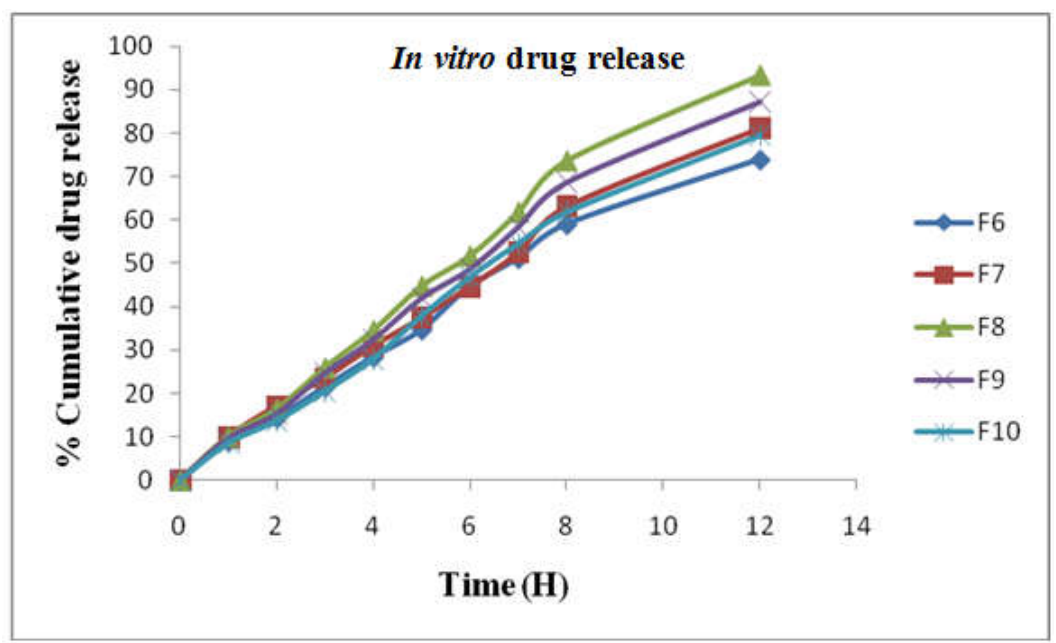

Fig. 5: In vitro diffusion studies for F7 to F12

The in vitro release information was exposed to zero, first order Higuchi's and Korsemeyers-Peppas model so as to set up the drug release means and kinetics involved. At the point, when the information was exposed to zero and first kinetics model, a straight relationship was seen with high $\mathrm{R}^{2}$ value for zero order models when contrasted with first order model and its proposed that the formulations obeyed zero order release. Higuchi's model was applied to the in vitro release information, linearity was gotten with 
high $\mathrm{R}^{2}$ values recommended that the drug discharge from the Nanosponges followed by different components. So as to characterize pefect model which will speak to a superior fit for in vitro release information, Korsemeyer-Peppas model was applied which will characterize the specific system. Great linearity with high $\mathrm{R}^{2}$ values was seen with this model. The estimation of $\mathrm{n}$ acquired for all the formulations was $>0.5$ and $<1.0$, recommending that the drug discharged followed non-fickianandiffusion.

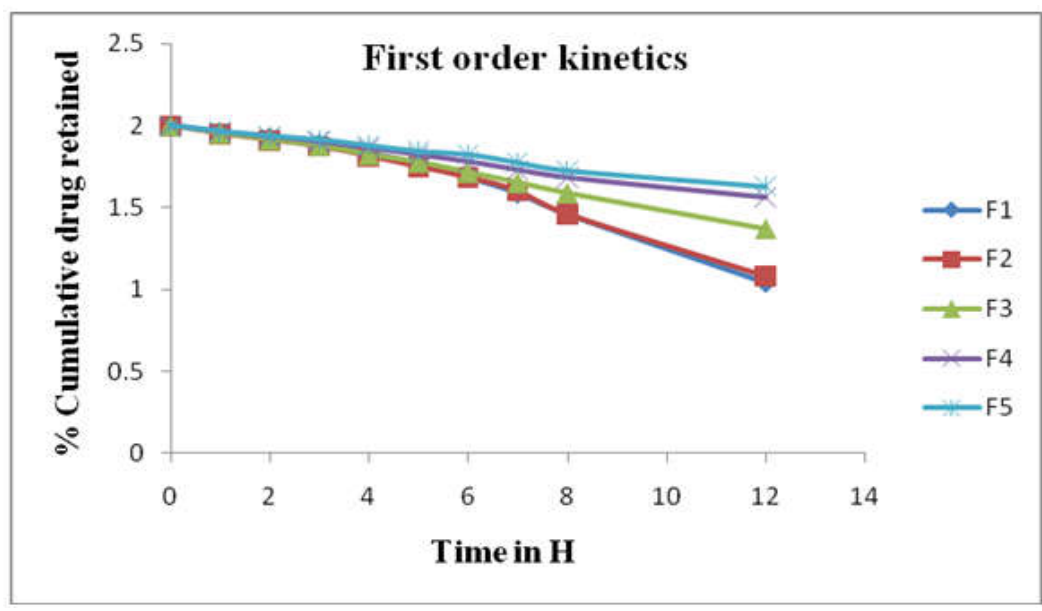

Fig. 6: Time Vs drug retained (First order kinetics) of formulations F1 to F5

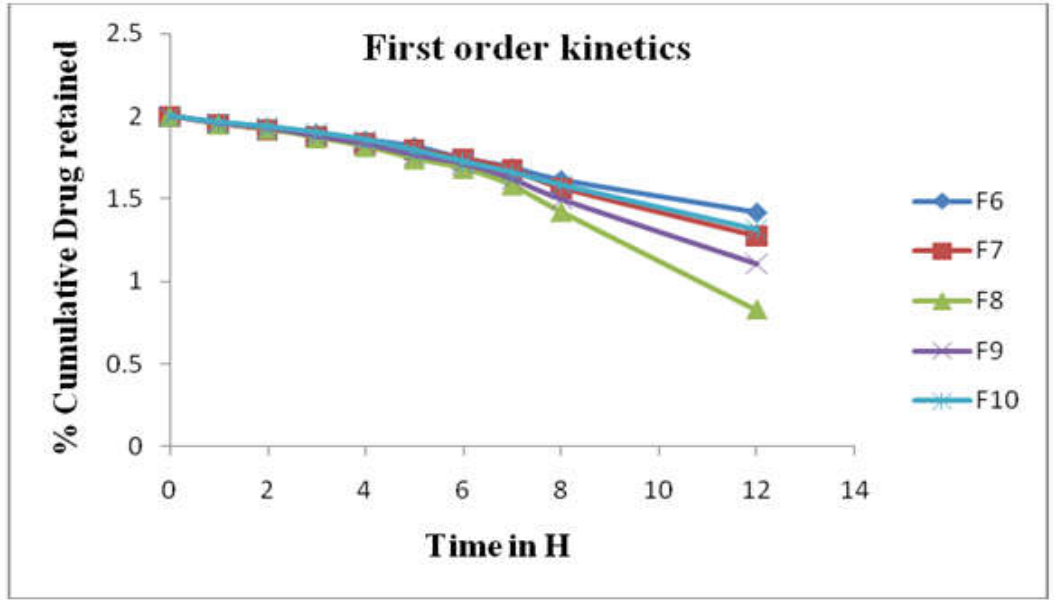

Fig. 7: Time Vs drug retained (First order kinetics) of formulations F6 to F10

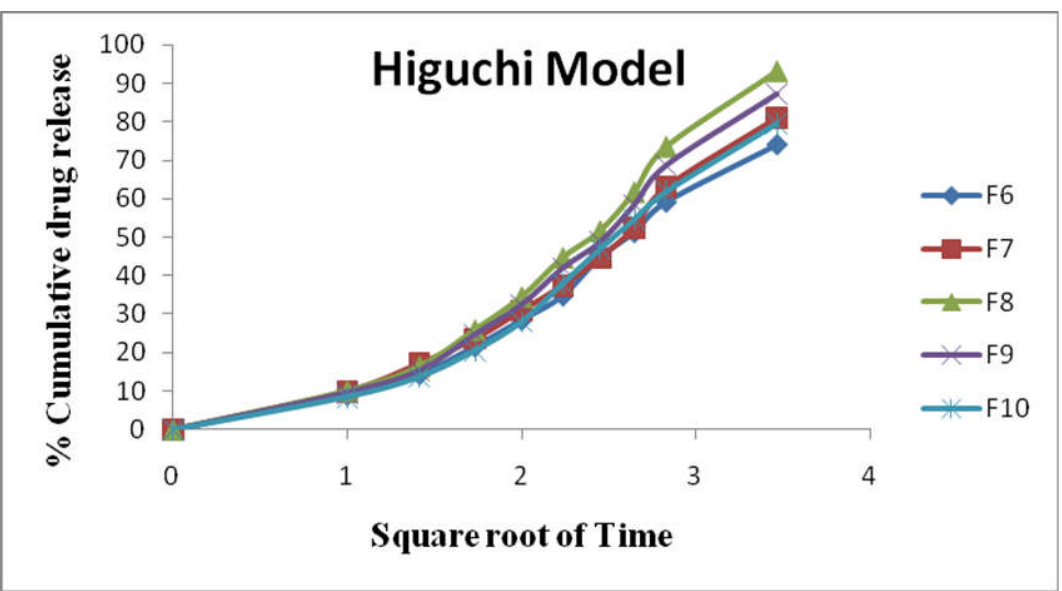

Fig. 8: Square root of time Vs \% cumulative drug released (Higuchi release mechanism) of formulation F1 to F5 


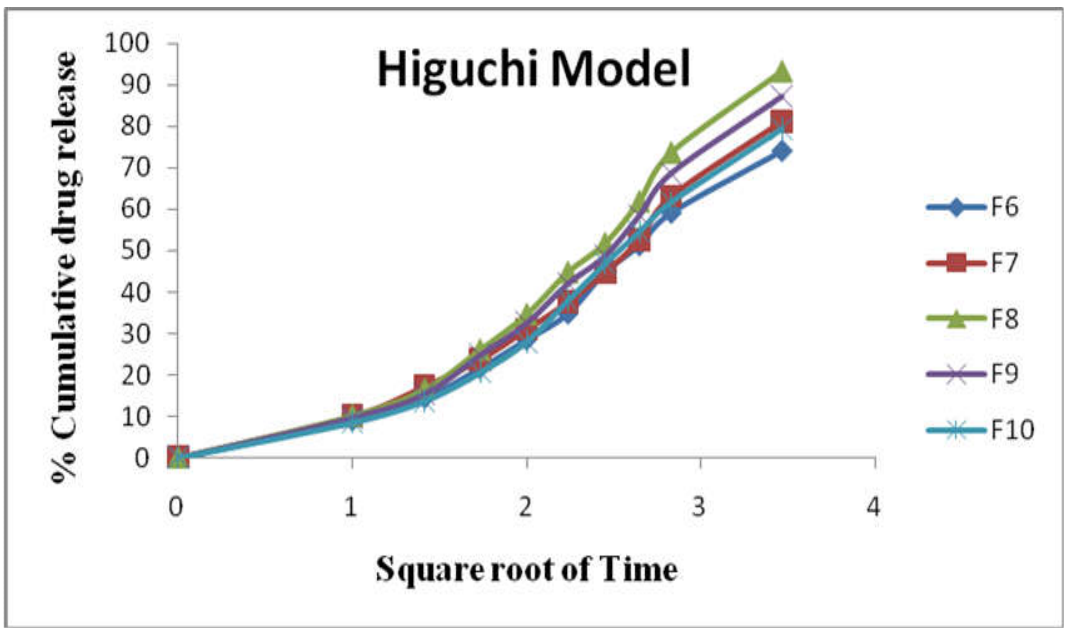

Fig. 9: Square root of time Vs \% cumulative drug released (Higuchi release mechanism) of formulation F6 to F10

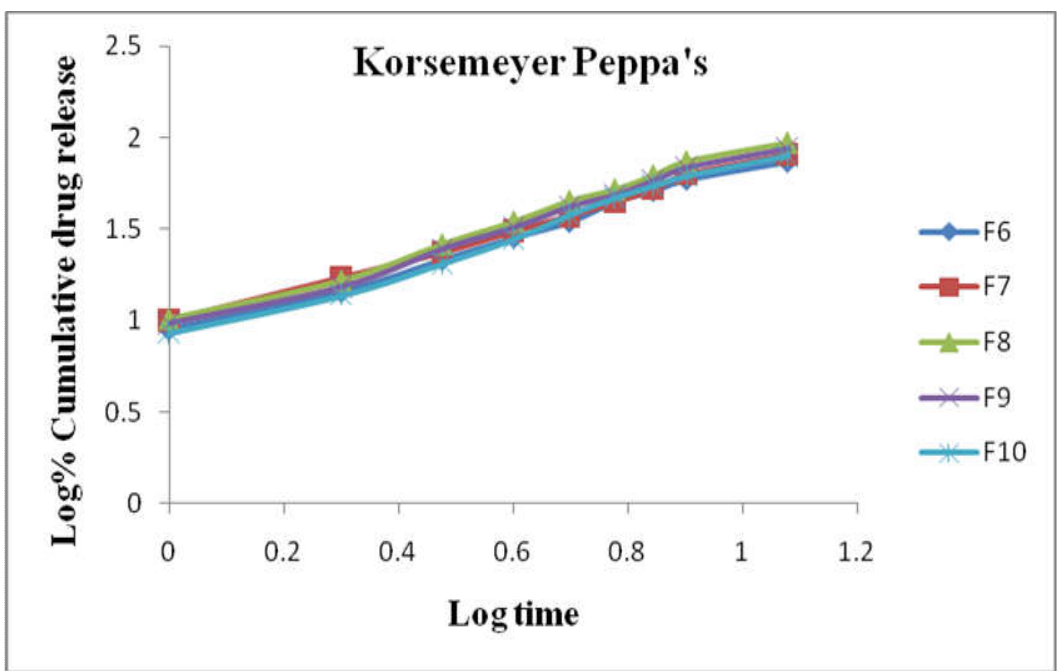

Fig. 10: Log time Vs cumulative \% drug released (Korsmeyer-peppas release mechanism) of formulations F1 to F5

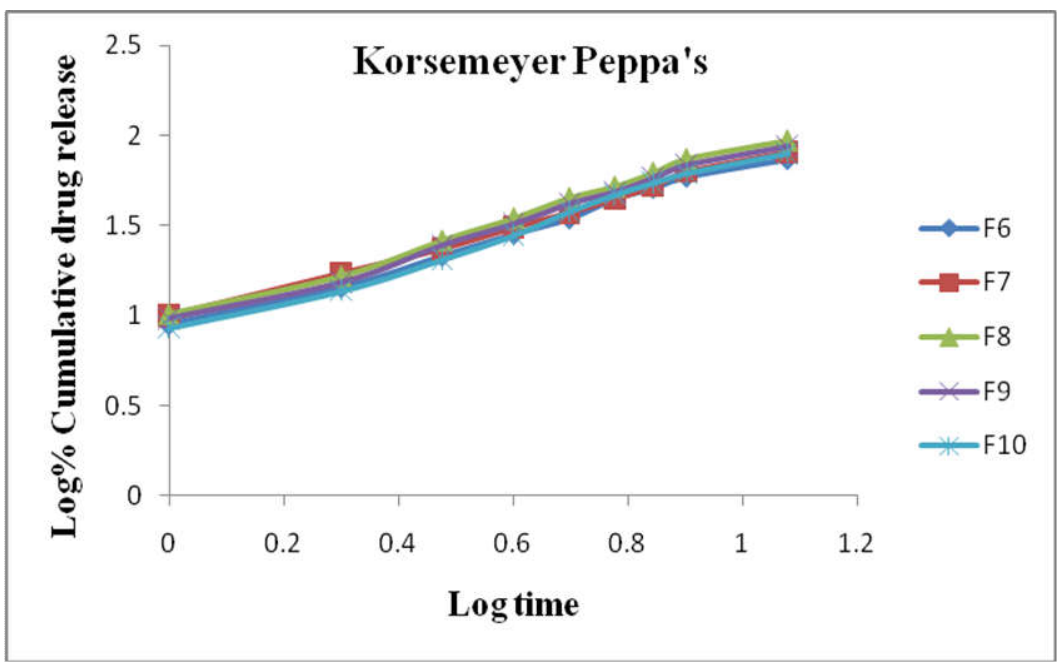

Fig. 11: Log time Vs cumulative \% drug released (Korsmeyer-peppas release mechanism) of formulations F6 to F10 
Table 3: Release kinetics data of the formulations F1 to F10

\begin{tabular}{|c|c|c|c|c|c|}
\hline \multirow[t]{2}{*}{ Formulation code } & \multirow[t]{2}{*}{ Zero order $\mathbf{R}^{2}$} & \multirow[t]{2}{*}{ First order $\mathbf{R}^{2}$} & \multirow[t]{2}{*}{${\text { Higuchi's } \mathbf{R}^{2}}^{2}$} & \multicolumn{2}{|c|}{ Korsemeyer peppa's } \\
\hline & & & & $\mathbf{n}$ & $\mathbf{R}^{2}$ \\
\hline F1 & 0.980 & 0.950 & 0.910 & 0.977 & 0.985 \\
\hline $\mathrm{F} 2$ & 0.981 & 0.960 & 0.932 & 0.892 & 0.993 \\
\hline F3 & 0.974 & 0.994 & 0.952 & 0.848 & 0.995 \\
\hline $\mathrm{F} 4$ & 0.972 & 0.994 & 0.947 & 0.861 & 0.994 \\
\hline F5 & 0.976 & 0.993 & 0.947 & 0.823 & 0.994 \\
\hline F6 & 0.981 & 0.986 & 0.928 & 0.901 & 0.991 \\
\hline F7 & 0.990 & 0.965 & 0.928 & 0.864 & 0.996 \\
\hline F8 & 0.986 & 0.915 & 0.920 & 0.946 & 0.993 \\
\hline F9 & 0.986 & 0.953 & 0.922 & 0.939 & 0.992 \\
\hline F10 & 0.983 & 0.977 & 0.915 & 0.964 & 0.988 \\
\hline
\end{tabular}

\section{CONCLUSION}

Diltiazem Nanospongesmade by solvent evaporation technique utilizing $\beta$-cyclodextrin and ethyl cellulose was assessed for its various parameters which uncovered many intriguing outcomes for productive production of the nanosponges. Nanosponges offer a simple and practical approach to achieve increased bioavailability, and modify drug release profiles essential for sustained, site specific and localized drug action. The investigation affirmed that all the readied Nanosponges have permeable structure and the drug content of formulations satisfied uniform distribution of drug within the drug delivery system. In vitro drug release studies indicated that, at $12 \mathrm{~h}$, ethyl cellulose containing formulationsreleased the drug in the range of $57.27-89.09 \%$ and for the $\beta$-cyclodextrin containing formulations drug released in the range of 73.94-93.26\%. Drug release is sustained in case of ethyl cellulose formulations compared to formulations containing $\beta$-cyclodextrin. Meanwhile, the in vitro diffusion obeyed zero order kinetics with mechanism of release zero order followed non fickian diffusion. So, Diltiazem $\mathrm{HCl}$ used for the treatment of angina as nonosponges can produce fast absorption. The study conducted so far reveals promising result suggesting scope for pharmacodynamic and pharmacokinetics evaluation. Thus, the developed nanosponges formulation may prove to be a promising carrier for Diltiazem $\mathrm{HCl}$ and other drugs, especially due to their simple production and simplistic scale up.

\section{FUNDING}

Nil

\section{AUTHORS CONTRIBUTIONS}

All the authors have contributed equally.

\section{CONFLICT OF INTERESTS}

Declared none

\section{REFERENCES}

1. Vishwakarma A, Nikam P, Mogal R, Talele S. Review on nanosponges: a beneficiation for novel drug delivery. Int J PharmTech Res 2014;6:11-20.

2. Yadav GV, Panchory HP. Nanosponges-a boon to the targeted drug delivery system. J Drug Delivery Ther 2013;3:151-5.

3. Rita L, Amit T, Chandrashekhar G. Current trends in $\beta$ cyclodextrin based drug delivery systems. Int J Res Ayurveda Pharm 2011;2:1520-6.
4. Shringirishi M, Prajapati SK, Mahor A, Alok S, Yadav P, Verma A. Nanosponges: a potential nanocarrier for novel drug delivery-a review. Asian Pacific J Trop Disease 2014;4:19-26.

5. Susmitha, Charanjit, Reddy VM, Naveena, Gupta VRM. Nanosponges-a concise review of emerging trends. Int J Pharm Res Biomed Anal 2014;3:1-6.

6. Challa R, Ahuja A, Ali J, Khar RK. Cyclodextrins in drug delivery: an updated review. AAPS PharmSciTech 2005;6:E329-57.

7. Khopade AJ, Jain S, Jain NK. The microsponge. East Pharm 1996;25:49-53.

8. Silpa JN, Nissankararao S, Bhimavarapu R, Sravanthi SL, Vinusha K, Renuka K. Nanosponges: a versatile drug delivery system. Int J Pharm Life Sci 2013;4:221-6.

9. Yang CY, Liao TC, Shuai HH, Shen TL, Yeh JA, Cheng CM. Micropatterning of mammalian cells on inorganic-based nanosponges. Biomaterials 2012;33:4988-97.

10. Bolmal UB, Manvi FV, Rajkumar K, Palla SS, Paladugu A, Reddy KR. Recent Advances in nanosponges as drug delivery system. Int J Pharm Sci Nanotechnol 2013;6:1934-44.

11. Sharma R, Pathak K. Polymeric nanosponges as an alternative carrier for improved retention of econazole nitrate onto the skin through topical hydrogel formulation. Pharm Dev Technol 2011;16:367-76.

12. Swaminathan $S$, Vavia PR, Trotta F, Cavalli R, Tumbiolo $S$, Bertinetti L, et al. Structural evidence of differentialforms of nanosponges of beta-cyclodextrin and its effect onsolubilization of a model drug. J Incl Phenom Macrocycl Chem 2012;76:201-11.

13. Bhowmik H, Venkatesh DN, Kuila A, Kumar KH. Nanosponges: a review. Int J Appl Pharm 2018;10:1-5.

14. Tambe RS, Battase PW, Arane PM, Palve SA, Talele SG, Chaudhari G. Review on nanosponges: as a targeted drug delivery system. Am J PharmTech Res 2015;5:215-24.

15. Subramanian SMK, Anandam S, Kannan KM, Rajappan M. Nanosponges: a novel class of drug delivery system-review. J Pharm Pharm Sci 2012;15:103-11.

16. Shankar S, Vavia PR, Francesco T, Satyen T. Formulation of betacyclodextrin based nanosponges of itraconazole. J Incl Phenom Macrocycl Chem 2007;57:89-94.

17. Nilesh J, Ruchi J, Navneet T, Brham P, Gupta, Deepak K, et al. Nanotechnology: a safe and effective drug delivery system. Asian J Phar Clin Res 2010;3:159-65.

18. Indira B, Bolisetti SS. Nanosponges: a new era in drug delivery. J Pharm Res 2012;5:5293-6. 